\title{
L'Opera incompiuta, testi raccolti e pubblicati da Lucia Omacini
}

\section{Paola Perazzolo}

\section{(2) OpenEdition}

\section{Journals}

\section{Édition électronique}

URL : http://journals.openedition.org/studifrancesi/6631

DOI : 10.4000/studifrancesi.6631

ISSN : 2427-5856

\section{Éditeur}

Rosenberg \& Sellier

\section{Édition imprimée}

Date de publication : 1 septembre 2010

Pagination : 365

ISSN : 0039-2944

\section{Référence électronique}

Paola Perazzolo, «L'Opera incompiuta, testi raccolti e pubblicati da Lucia Omacini », Studi Francesi [En ligne], 161 (LIV | II) | 2010, mis en ligne le 30 novembre 2015, consulté le 13 janvier 2021. URL : http:// journals.openedition.org/studifrancesi/6631; DOI : https://doi.org/10.4000/studifrancesi.6631

Ce document a été généré automatiquement le 13 janvier 2021.

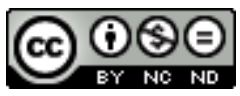

Studi Francesi è distribuita con Licenza Creative Commons Attribuzione - Non commerciale - Non opere derivate 4.0 Internazionale. 


\title{
L'Opera incompiuta, testi raccolti e pubblicati da Lucia Omacini
}

\author{
Paola Perazzolo
}

\section{RÉFÉRENCE}

L'Opera incompiuta. Testi raccolti e pubblicati da Lucia OMACINI, «Annali di Ca' Foscari», XLVII, n. 2, 2008, pp. 7-38, 155-167.

1 Curato da L. Omacini, specialista di letteratura francese del Settecento che da tempo si interessa alle forme frammentarie e al fenomeno dell'inachèvement nelle sue varie modalità, il presente volume raccoglie vari studi sulla disgregazione formale e/o tematica e sull'articolazione del non finito nella produzione letteraria di diversi secoli e culture, senza limitarsi all'epoca contemporanea. Come da tradizione di «Studi Francesi», ci proponiamo qui - nonostante l'interesse dell'intero testo, che permette il confronto tra culture, periodi e forme letterarie differenti - di rendere conto dei due contributi attinenti alla letteratura francese. In La poétique de l'inachèvement mise en œuvre par le roman au XVII et XVIII ${ }^{e}$ siècles (pp. 19-38), Jean-Paul SERMAIN affronta il tema dell'incompiutezza narrativa dal Don Quichotte a Madame Bovary, sottolineando le diverse modalità formali e concettuali che il fenomeno può assumere. Se in alcuni casi l'incompiutezza è accidentale, in altri il non finito esprime una scelta poetica, così che l'opera trova nell'imperfezione il suo compimento. In ogni caso, la scelta di un particolare tipo di fine (o l'assenza della stessa) traduce una visione socio-culturale ben precisa, che si ritrova da un lato nella conclusione «en bonne et due forme» dei romanzi ottocenteschi sottesi da una concezione deterministica dell'esistenza, e dall'altro nelle forme più aperte dei testi precedenti sottesi da un'estetica differente. In Dal «divertissement forain» all' «ambigu-comique»: l'arte di frantumare e di combinare (pp. 155-166), Paola MARTINUZZI rivolge invece la sua attenzione alla produzione teatrale forense della prima metà del Settecento, produzione caratterizzata da un'incompiutezza e un'instabilità che si esplicita nel collage di materiali variegati e 
preesistenti e nella contaminazione non solo di testi, ma anche di modelli e stili per dar vita ad un processo di ri-creazione continua.

\section{AUTEURS}

PAOLA PERAZZOLO

it 